\title{
ANALYSIS OF SHEAR DESIGN RECOMMENDATIONS FOR FRP REINFORCED CONCRETE BEAMS
}

\author{
Marius BUDVYTIS ${ }^{1}$, Alfonso COBO ESCAMILLA ${ }^{2}$, Linas JUKNEVIČIUS ${ }^{3}$ \\ ${ }^{1,3}$ Vilnius Gediminas Technical University, Sauletekio al. 11, LT-10223 Vilnius, Lithuania \\ ${ }^{2}$ Universidad Politécnica de Madrid, Av. Juan de Herrera 6m, 28040 Madrid, Spain
}

Received 24 April 2018; accepted 7 June 2018

\begin{abstract}
Research shows that most shear design models for concrete beams reinforced with FRP reinforcement provide conservative results that leads to excessive amounts of reinforcement and increased overall cost of such construction. This paper presents comparative analysis of current shear design models for concrete beams reinforced with longitudinal FRP reinforcement and FRP stirrups. New analytical shear design model, developed by Valivonis et al., has been included in the analysis. A database with 88 specimens reinforced with FRP reinforcement was compiled in order to verify the accuracy of the proposed model by Valivonis et al. It is shown that proposed shear design model yields quite accurate and consistent results as an average of $V_{\text {exp }} / V_{\text {pred }}$ values is 0.98 and coefficient of variation is $26.0 \%$ for this model.
\end{abstract}

Keywords: shear strength, fiber reinforced polymer bar, stirrup, reinforced concrete.

\section{Introduction}

Working life of steel reinforced concrete structures is shortened by steel reinforcement corrosion. Maintenance and repair of such damaged structures is very expensive. Corrosion is particularly dangerous for structures in aggressive marine environment or unprotected from the effect of deicing salts. Working life of such structures is highly dependent on the durability of reinforcement. Fiber-reinforced polymer (FRP) reinforcement is more durable than steel reinforcement so it can be considered as more advantageous alternative to steel reinforcement when using it to reinforce concrete structures exposed to aggressive environment. Reinforcement, located closest to the surface of the element (e.g. shear reinforcement in beams), is the most vulnerable to aggressive environmental effects. For this reason, employment of FRP shear reinforcement in such cases is even more meaningful. Use of FRP reinforcement in the manufacture of such structures can potentially extend it's working life and reduce overall life cycle cost. For example, it is reported that billions of dollars are spent every year in North America for repair and replacement of pile systems (Benmokrane, Ali, Mohamed, Robert, \& ElSafty, 2016; Mohamed, Afifi, \& Benmokrane, 2014). Also it was determined that repair of all steel reinforced concrete structures in Canada would cost about 74 billion dollars (Natural Sciences and Engineering Research Council of Canada, 2010).

Up to now FRP reinforcement was successfully used as main structural reinforcement in construction of various concrete bridges, underground parking lots, tunnels (Nanni \& Faza, 2002; Mohamed \& Benmokrane, 2013). Therefore research, development and practical use of concrete structures reinforced with FRP reinforcement recently has gained more and more interest in the field of civil engineering.

\section{Review of the current design provisions}

The main differences of FRP reinforcement compared to steel reinforcement are lower modulus of elasticity and linear elastic behavior up to rupture. Also when using FRP reinforcement as shear stirrups in beams, it must be evaluated that tensile strength of the bent part of the FRP reinforcement bar is significantly lower than that of the straight part (Shehata, Morphy, \& Rizkalla, 2000; El-Sayed, El-Salakawy, \& Benmokrane, 2007). Shear strength of FRP reinforced elements is affected by the mentioned mechanical properties of FRP reinforcement. For this reason, these mechanical properties should be taken into account in the shear design equations.

*Corresponding author. E-mail: marius.budvytis@vgtu.lt 
So far a number of detailed studies have been carried out in order to perform comprehensive shear analysis of concrete structures reinforced with FRP reinforcement (Shehata et al., 2000; Razaqpur \& Spadea, 2014; Alam \& Hussein, 2012; Bentz, Massam, \& Collins, 2010; Ahmed, El-Salakawy, \& Benmokrane, 2010; Fico, Prota, \& Manfredi, 2008; El-Sayed \& Benmokrane, 2008; El-Sayed, El-Salakawy, \& Benmokrane, 2006; Alkhrdaji, Wideman, Belarbi, \& Nanni, 2001; Guadagnini, Pilakoutas, \& Waldron, 2006; Tottori \& Wakui, 1993). Calculation methods and design standards were created to determine element's shear capacity. These include ACI 440.1R-06 (American Concrete Institute, 2006), CNR-DT 203/2006 (Italian Research Council, 2007), CSA S806-12 (Canadian Standards Association, 2012), CSA S6-14 (Canadian Standards Association, 2014) and JSCE (Japan Society of Civil Engineering, 1997). Shear design models in these standards are based on a theory that shear capacity of reinforced concrete beam consists of concrete shear resistance $V_{c}$ and FRP transverse reinforcement shear resistance $V_{f}$. However, research shows that these models provide conservative shear capacity predictions of FRP reinforced elements. Therefore new design models are constantly being developed and researchers are looking for more precise methods for determining shear resistance.

For instance, Hoult, Sherwood, Bentz, and Collins (2008) developed shear design model for FRP reinforced beams based on modified compression field theory (MCFT). The results of Hoult et al. research showed that shear behavior of FRP reinforced beams without shear reinforcement is very similar to that of steel reinforced beams. This was later confirmed by the results of Bentz et al. (2010) research. Also, it is worth mentioning that Perera, Arteaga, and Diego (2010) developed new calculation method based on artificial intelligence techniques.

Through this section, shear strength calculation equations as specified by the ACI 440.1R-06, CNR-DT 203/2006, CSA S806-12, CSA S6-14, Oller, Mari, Bairan, and Cladera (2015), Hegger, Niewels, and Kurth (2009), Nehdi, El Chabib, and Aly Said (2007) will be reviewed.

According to ACI 440.1R-06, CNR-DT 203/2006, CSA S806-12, CSA S6-14, Hegger et al. (2009) and Nehdi et al. (2007) shear design models, shear resistance is calculated using this equation:

$$
V_{u}=V_{c}+V_{f}
$$

where: $V_{c}$ - concrete contribution to shear capacity; $V_{f}$ FRP contribution to the shear capacity.

\section{ACI 44.1R-06}

New design model for concrete shear resistance was proposed by Tureyen and Frosch (2002). ACI 440.1R-06 adopted this method and concrete shear resistance according to it is expressed as:

$$
\begin{aligned}
& V_{c}=\frac{2}{5} \sqrt{f_{c}} b_{w} c \\
& c=k d
\end{aligned}
$$

$$
\begin{aligned}
& k=\sqrt{2 \rho_{f} n_{f}+\left(\rho_{f} n_{f}\right)^{2}}-\rho_{f} n_{f} ; \\
& n_{f}=E_{f} / E_{c},
\end{aligned}
$$

where $b_{w}$ - beam width; $c$ - depth of compression zone at cracked transformed section; $d$ - effective depth; $k$ - coefficient, which accounts the decreasing depth of neutral axis; $E_{f}$ - modulus of elasticity of longitudinal FRP reinforcement; $E_{c}$ - modulus of elasticity of concrete.

Equation (2) is shear capacity equation for steel reinforcement, modified by the empirically determined factor which accounts for the axial stiffness of the FRP reinforcement.

Equation for shear resistance provided by shear reinforcement $V_{f}$ is based on a modified truss analogy. It is assumed that total shear is carried by the shear reinforcement in this model. Shear capacity provided by FRP shear reinforcement:

$$
\begin{aligned}
& V_{f}=\frac{f_{f w} A_{f w} d}{s} ; \\
& f_{f w}=0.004 E_{f w} \leq f_{f b} ; \\
& f_{f b}=\left(0.05 \cdot \frac{r_{b}}{d_{b}}+0.3\right) f_{f w u},
\end{aligned}
$$

where $f_{f w}$ - stress level in the FRP shear reinforcement at ultimate state; $A_{f w}$ - area of FRP shear reinforcement; $s$ - spacing of shear reinforcement; $f_{f b}$ - tensile strength of FRP bent bar; $r_{b}$ - bending radius of FRP bar; $d_{b}$ - diameter of the FRP bar in the bent portion.

\section{CNR-DT 203/2006}

According to CNR-DT 203/2006, limitation of shear capacity of FRP reinforced elements using FRP stirrups shall be satisfied:

$$
V_{u} \leq V_{u, \max },
$$

where $V_{u, \max }$ - concrete contribution corresponding to shear failure due to crashing of the web.

Formula for calculating concrete shear resistance is a modified version of the Eurocode 2 shear equation for conventional steel RC members. Concrete shear resistance according to CNR-DT 203/2006:

$$
\begin{aligned}
& V_{c}=1.3 \cdot\left(\frac{E_{f}}{E_{s}}\right)^{1 / 2} \cdot \tau \cdot k \cdot\left(1.2+40 \rho_{f}\right) \cdot b_{w} \cdot d ; \\
& \tau=0.25 f_{c t} ; \\
& k=1.6-d \geq 1,
\end{aligned}
$$

where: $E_{s}$ - modulus of elasticity of steel reinforcement; $\tau$ - shear stress; $\rho_{f}$ - longitudinal FRP reinforcement ratio.

The main difference between CNR-DT 203/2006 and Eurocode 2 equations is that additional limitation shall be satisfied. This limitation is presented because experimental results showed that the shear contribution of FRP shear reinforcement is lower than steel in the case of RC beams 
with FRP stirrups:

$$
1.3 \cdot\left(\frac{E_{f}}{E_{s}}\right)^{1 / 2} \leq 1 \text {. }
$$

Shear capacity provided by FRP shear reinforcement can be calculated using the following equation:

$$
\begin{aligned}
& V_{f}=\frac{A_{f w} \cdot f_{f r} \cdot d}{s} ; \\
& f_{f r}=f_{f w u} / \gamma_{f, \Phi},
\end{aligned}
$$

where $f_{f r}$ - reduced tensile strength of the FRP reinforcement; $f_{f w u}$ - tensile strength of FRP shear reinforcement; $\gamma_{f \Phi}-$ partial factor to account for the bending effect (shall be set equal to 2 when no specific experimental tests are performed).

$$
\begin{aligned}
& V_{u, \max }=\frac{\alpha_{c w} b_{w} z v_{1} f_{c}}{\operatorname{ctg} \theta+\operatorname{tg} \theta} ; \\
& z=0.9 d ; \\
& v_{1}=0.6\left[1-\left(\frac{f_{c}}{250}\right)\right] ; \\
& \operatorname{ctg} \theta=\sqrt{\frac{\alpha_{c w} b_{w} v_{1} f_{c} s}{A_{f w} f_{f w}}-1,}
\end{aligned}
$$$$
V_{u, \max } \text { can be calculated as follows: }
$$

where $\theta$ - angle between the concrete compression strut and the beam axis perpendicular to the shear force; $\alpha_{c w}-$ coefficient taking into account the state of the stress in the compression chord; $v_{1}$ - strength reduction factor for concrete cracked in shear.

\section{CSA S806-12}

Canadian Standards Association uses shear design model which is theoretically derived and based on strut-and-tie model for FRP reinforcement. According to CSA S80612 design recommendations, shear capacity of FRP reinforced concrete beam is also limited:

$$
V_{u} \leq 0.22 \phi_{c} f_{c} b_{w} z,
$$

where $\phi_{c}$ - resistance factor for concrete.

Concrete shear capacity can be evaluated using this equation:

$$
\begin{aligned}
& V_{c}=0.05 \lambda \phi_{c} \cdot k_{m} \cdot k_{r} \cdot f_{c}^{1 / 3} \cdot b_{w} \cdot z ; \\
& k_{m}=\sqrt{d / a} \leq 1.0 ; \\
& k_{r}=1+\left(E_{f} \rho_{f}\right)^{1 / 3},
\end{aligned}
$$

where $\lambda$ - factor accounting for concrete density; $a$ is shear span.

FRP reinforcement shear capacity is given by:

$$
\begin{aligned}
& V_{f}=\left(\frac{\phi_{f} A_{f w} f_{f w} z}{s}\right) \operatorname{ctg} \theta ; \\
& f_{f w}=0.005 E_{f w} \leq 0.4 f_{f w u} ; \\
& \theta=30+7000 \varepsilon_{x} ;
\end{aligned}
$$

$$
\varepsilon_{x}=\frac{(M / z)+V}{2\left(E_{f} A_{f}\right)} \leq 0.003,
$$

where $\phi_{f}$ - resistance factor for FRP reinforcement; $\varepsilon_{x}-$ longitudinal strain at midheight of the cross section; $M$ bending moment; $V$ - shear load; $A_{f}-$ area of FRP longitudinal reinforcement.

\section{CSA S6-14}

Canadian Highway Bridge Design Code also uses strutand-tie models for shear capacity calculation of concrete beams. Concrete shear resistance according to CSA S6-14:

$$
\begin{aligned}
V_{c} & =2.5\left[\frac{0.4}{\left(1+1500 \varepsilon_{x}\right)} \cdot \frac{1300}{\left(1000+s_{z e}\right)}\right] f_{c r} b_{w} z ; \\
\varepsilon_{x} & =\frac{(M / z)+V}{2\left(E_{f} A_{f}\right)} \leq 0.003 ; \\
s_{z e} & =300 \mathrm{~mm} ; \\
f_{c r} & =0.4 \sqrt{f_{c}},
\end{aligned}
$$

where: $s_{z e}$ - effective crack spacing for members without stirrups; $f_{c r}$ - cracking strength of concrete.

Shear capacity provided by FRP shear reinforcement:

$$
\begin{aligned}
& V_{f}=\left(\frac{\phi_{f} A_{f w} f_{f w} z}{s}\right) \operatorname{ctg} \theta ; \\
& f_{f w}=0.004 E_{f w} \leq f_{f b} ; \\
& f_{f b}=\frac{\left(0.05 r_{b} / d_{b}+0.3\right) f_{f w u}}{1.5} ; \\
& \theta=\left(30+7000 \varepsilon_{x}\right)\left(0.88+\frac{s_{z e}}{2500}\right) .
\end{aligned}
$$

\section{Hegger et al.}

Equation of concrete shear resistance is similar to the equation of shear design model given in Eurocode 2 with some parameters that evaluate unique FRP longitudinal reinforcement characteristics. These parameters were determined through experimental tests. Concrete shear resistance is expressed as:

$$
\begin{aligned}
& V_{c}=k_{f} \cdot \beta \cdot 0.205 \cdot \kappa \cdot\left(100 \cdot \rho_{f} \cdot \frac{E_{f}}{E_{s}} \cdot f_{c}\right)^{1 / 3} \cdot b_{w} \cdot d ; \\
& k_{f}=1-10 \cdot \rho_{f w} \cdot \frac{E_{f w}}{E_{c}} ; \\
& \beta=3 \cdot \frac{d}{a} \\
& \kappa=1+\sqrt{200 / d} .
\end{aligned}
$$

FRP transverse reinforcement shear capacity depends on a limit stirrup strain based on the results of existing experimental work. Shear capacity provided by FRP shear reinforcement:

$$
V_{f}=\min \left(\frac{A_{f w} \cdot f_{f w} \cdot z \cdot \operatorname{ctg} \theta}{s} ; b_{w} \cdot z \cdot \alpha_{c} \cdot f_{c} \cdot \frac{1}{\operatorname{ctg} \theta+\operatorname{tg} \theta}\right) ;
$$




$$
\begin{aligned}
& f_{f w}=\min \left(0.4 \cdot f_{f w u} ; E_{f w} \cdot \varepsilon_{f w u}\right) ; \\
& \varepsilon_{f w u}=3+\frac{0.015}{\left(\rho_{f w} \cdot E_{f w} / E_{c}\right)} ; \\
& \alpha_{c}=0.2 .
\end{aligned}
$$

\section{Nehdi et al.}

Nehdi et al. (2007) developed equations to calculate the shear capacity of FRP reinforced concrete beams based on the genetic algorithms approach. In training and testing of the model $f_{c}, b_{w}, d, a / d, E_{f} / E_{s}, \rho_{f}, \rho_{f w}, f_{f w u}$ were entered as input variables. Study performed by these authors showed that the axial rigidity of FRP longitudinal bars is best represented by a cubic root function and that the contribution of FRP stirrups to shear strength is a square root function of the stirrups ultimate capacity rather than a linear function as proposed by current shear provisions.

Concrete shear resistance is calculated according to this equation:

$$
\begin{aligned}
& V_{c}=2.1\left(\frac{f_{c} \rho_{f} d}{a} \frac{E_{f}}{E_{s}}\right)^{0.3} b_{w} d, \text { when } a / d \geq 2.5 ; \\
& V_{c}=2.1\left(\frac{f_{c} \rho_{f} d}{a} \frac{E_{f}}{E_{s}}\right)^{0.3} b_{w} d \cdot \frac{2.5 d}{a}, \text { when } a / d<2.5 .
\end{aligned}
$$

Transverse FRP reinforcement shear resistance:

$$
V_{f}=0.5\left(\rho_{f w} f_{f w u}\right)^{0.5} b_{w} d .
$$

\section{Oller et al.}

Oller et al. (2015) developed shear design model that is based on the principles of structural mechanics and on the observed experimental behaviour of FRP reinforced concrete beams with FRP transverse reinforcement. Each shear transfer mechanism has been included and evaluated in this model.

Ultimate shear strength of FRP reinforced concrete beam is calculated using this equation:

$$
V_{u}=V_{c c}+V_{w}+V_{t}=f_{c t} \cdot b_{w} \cdot d \cdot\left(v_{c c}+v_{w}+v_{t}\right),
$$

where: $V_{c c}$ - shear resisted by the un-cracked concrete zone; $V_{w}$ - shear resisted by tensile stresses transferred along the crack; $V_{t}$ - shear resisted by transverse reinforcement crossing the diagonal critical shear crack; $v_{c c}$, $v_{w}, v_{t}$ - dimensionless forms of shear resisted by the uncracked concrete zone, by tensile stresses transferred along the crack and by transverse reinforcement crossing the diagonal critical shear crack, respectively.

Shear resistance of un-cracked concrete zone:

$$
v_{c c}=\zeta \cdot(1.072-0.01 \cdot \alpha) \cdot\left(\left(0.98+0.22 \cdot v_{t}\right) \cdot \xi+0.05\right) \text {; }
$$

$\zeta=1.2-0.2 \cdot a \geq 0.65 ;$

$$
\alpha=E_{f} / E_{c}
$$

$$
\xi=\alpha \cdot \rho_{f} \cdot\left(-1+\sqrt{1+\frac{2}{\alpha \cdot \rho_{f}}}\right),
$$

where: $\zeta$ - coefficient which accounts the size effect on the shear failure; $\xi$ - relative neutral axis depth.

Equation for the shear transferred by the crack:

$$
\begin{aligned}
& v_{w}=\frac{0.386}{\varepsilon_{f w, m}} \cdot \frac{f_{c t}}{E_{c}} \cdot\left(1+\frac{8 \cdot G_{f} \cdot E_{c}}{f_{c t}^{2} \cdot d}\right) ; \\
& \varepsilon_{f w, m}=0.225 \cdot \varepsilon_{f w u} ; \\
& G_{f}=0.028 \cdot f_{c}^{0.18} \cdot d_{\max }^{0.32},
\end{aligned}
$$

where: $\varepsilon_{f w, m}$ - mean strain at the stirrups crossing the crack; $f_{c t}$ - concrete tensile strength; $G_{f}$ - fracture energy of concrete; $\varepsilon_{f w u}$ - ultimate strain of the transverse FRP stirrups; $d_{\max }$ - maximum aggregate size.

The contribution of the FRP stirrups can be expressed as:

$$
v_{t}=\frac{\rho_{f w} \cdot 0.85 \cdot E_{f w} \cdot \varepsilon_{f w, m}}{f_{c t}} .
$$

\section{Proposed shear design model}

Proposed shear design model by Valivonis, Budvytis, Atutis, M., Atutis, E., and Juknevičius (2015) will be included in the comparison and analysis of calculation methods. This shear design model is described in more detail in the paper of Valivonis et al. (2015). Here only final equations for calculating shear resistance are given.

This design model is based on the assumption that shear strength consists of concrete shear capacity and FRP transverse reinforcement shear capacity. Following equation is recommended for calculating concrete shear capacity:

$$
\begin{aligned}
& V_{c}=\frac{\varphi_{c 2} \varphi_{f} f_{c t} b_{w} d^{2}}{a} \geq \varphi_{c 3} \varphi_{f} f_{c t} b_{w} d ; \\
& \varphi_{f}=0.4 \cdot\left(\frac{E_{f}}{E_{s}}\right)^{\rho_{f}} ; \\
& a \leq \frac{\varphi_{c 4}}{\varphi_{c 3}} d ; \\
& \varphi_{c 2}=2.0 ; \varphi_{c 3}=0.45 ; \varphi_{c 4}=1.5,
\end{aligned}
$$

where: $\varphi_{c 2}, \varphi_{c 3}, \varphi_{c 4}$ - coefficients which estimate concrete's properties; $\varphi_{f}$-coefficient which estimate the influence of FRP flexural reinforcement for the concrete shear resistance.

FRP transverse reinforcement shear capacity is expressed as:

$$
\begin{aligned}
& v_{f}=v_{f w} a_{0} ; \\
& v_{f w}=\frac{f_{f w} A_{f w}}{s} ; \\
& a_{0}=\sqrt{\frac{\varphi_{c 2} f_{c t} b_{w} d^{2}}{v_{f w}}} ;
\end{aligned}
$$




$$
\begin{aligned}
& d \leq a_{0} \leq \min \left\{\begin{array}{l}
2 d \\
a
\end{array} ;\right. \\
& f_{f w}=\varepsilon_{f w} \cdot E_{f w} ; \\
& \varepsilon_{f w}=\sqrt{\left(\frac{h}{0.85}\right)^{-1.5} f_{c} \frac{\rho_{f} E_{f}}{\rho_{f w} E_{f w}}} \cdot 10^{-4} \leq 0.0045,
\end{aligned}
$$

where $a_{0}$ - critical projection of shear cracking zone, where FRP shear reinforcement contributes to shear strength of concrete beam.

\section{Database of beams reinforced with flexural and shear FRP reinforcement}

The performance of the proposed model for predicting the ultimate shear capacity is evaluated in this section together with other reviewed shear design models. In this analysis, only beams with longitudinal and shear FRP reinforcement were analyzed.

As shown in Table 1, 88 specimens with FRP shear reinforcement were analyzed. The collected database included beams reinforced with different amounts and types of reinforcement - aramid, carbon and glass FRP reinforcement.

\section{Comparison of shear strength predictions with experimental results}

In order to determine the relative accuracy of the proposed shear design model and to compare it with the other available shear design models, comparison of experimental and theoretical shear strength values was performed. Table 2 presents the mean, the standard deviation and the coefficient of variation of the ratio of experimental to predicted shear strengths of the specimens. Also the results of this analysis are shown in Figures 1-8, where correlation between the experimental shear force $V_{\text {exp }}$ and the theoretical prediction $V_{\text {pred }}$ is presented.

According to the data in the Table 2, the mean value of $V_{\text {exp }} / V_{\text {pred }}$ is 0.98 with standard deviation of 0.26 and coefficient of variation of $26.0 \%$ for proposed shear design model of FRP reinforced concrete beams. According to these results, systematic error is 0.02 and random error is equal to 0.26 for this calculation model. These results are similar to the results of CSA S806-12 and Hegger et al. (2009) shear design models. Statistical analysis results show that proposed model, CSA S806-12 and Hegger et al. (2009) models are the most accurate models.

Also it should be noted that model of CNR-DT $203 / 2006$ gives the least standard deviation of 0.16 . This parameter is used to quantify the amount of dispersion of a set of data values. It means that despite of the fact that compiled database included specimens reinforced with different types and different amounts of FRP reinforcement, dispersion of $V_{\text {exp }} / V_{\text {pred }}$ values is quite small.

It can be observed that shear design models of ACI 440.1R-06 and CSA S6-14 are quite conservative with very high mean value, standard deviation and coefficient of variation of $V_{\text {exp }} / V_{\text {pred }}$ values.

Design model of Nehdi et al. (2007) is based on the genetic algorithms approach. The mean value of $V_{\text {exp }} / V_{\text {pred }}$ is 1.23 with standard deviation of 0.27 and coefficient of variation of $22.1 \%$ for this model. Statistical analysis data of this model show that genetic algorithms approach may also be used in developing new shear design models for FRP reinforced concrete beams.

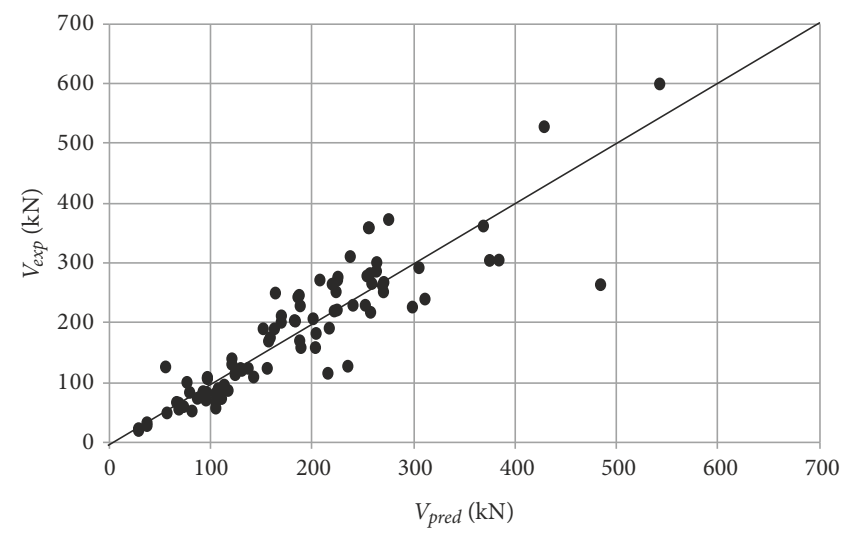

Figure 1. Experimental $V_{\text {exp }}$ versus predicted $V_{\text {pred }}$ shear strength by the proposed shear design model



Figure 2. Experimental $V_{\text {exp }}$ versus predicted $V_{\text {pred }}$ shear strength by the ACI 440.1R-06 shear design model

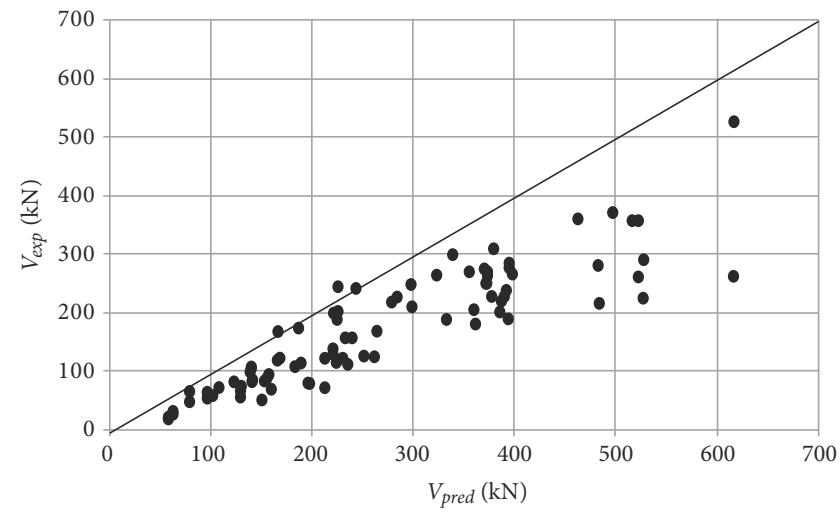

Figure 3. Experimental $V_{\text {exp }}$ versus predicted $V_{\text {pred }}$ shear strength by the CNR-DT 203/2006 shear design model 


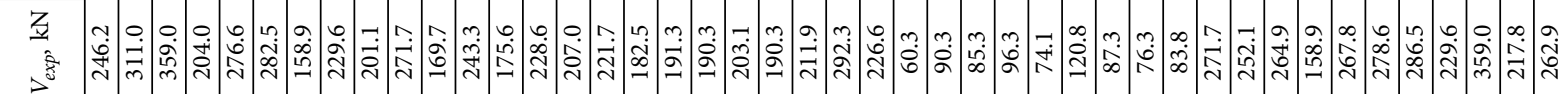

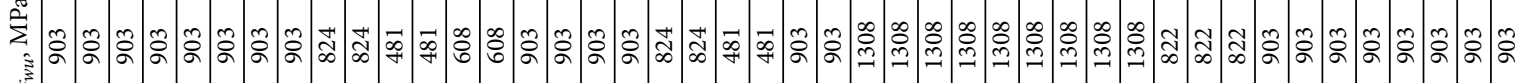
ڤึ

苞借

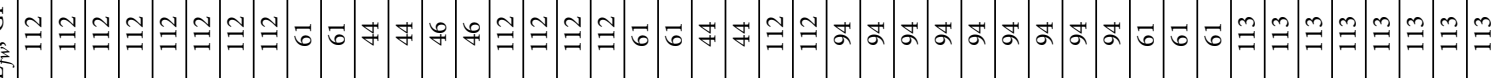

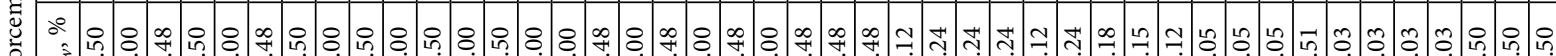

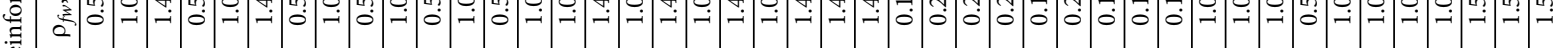

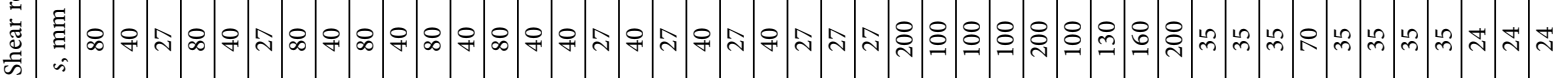

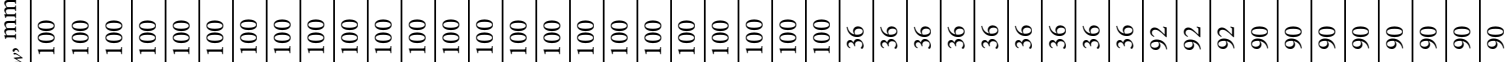
के

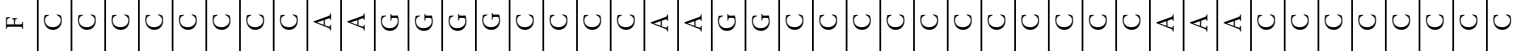

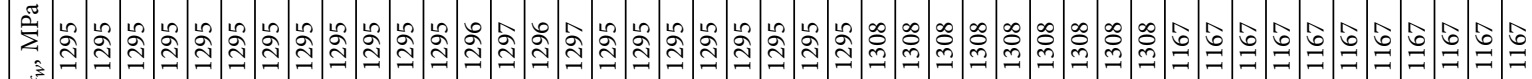

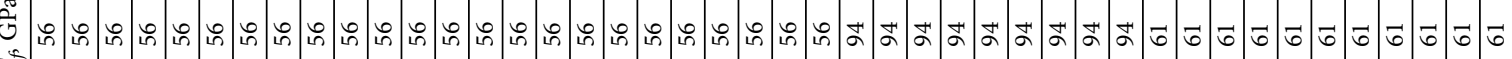

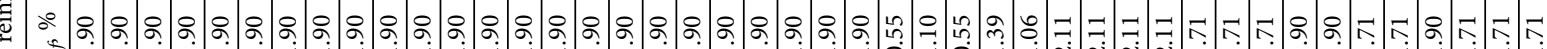
密

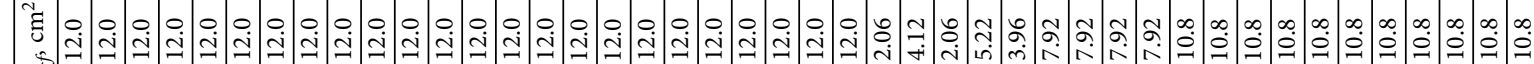

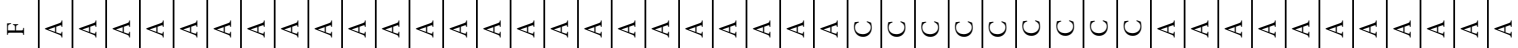

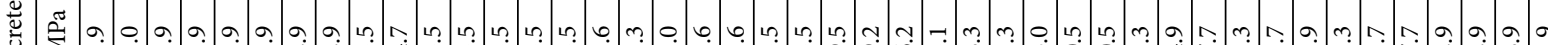

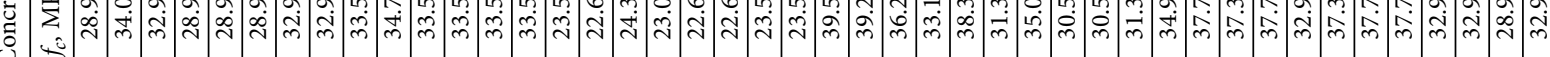

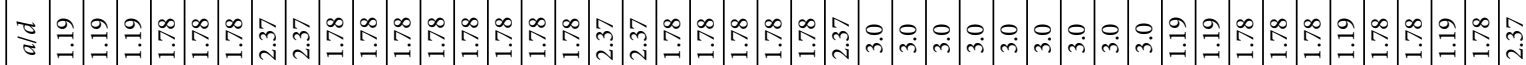
E

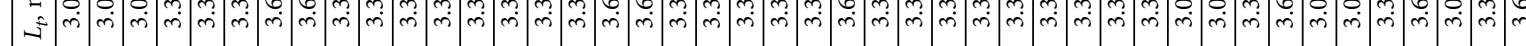

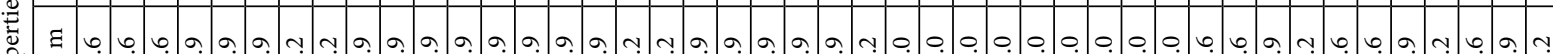

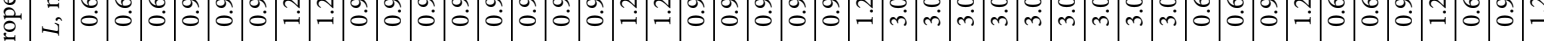

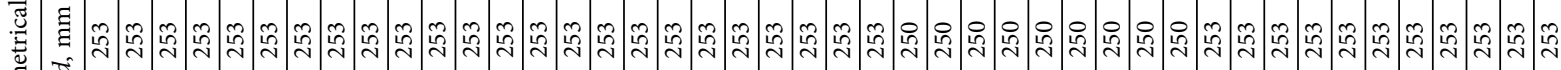
.

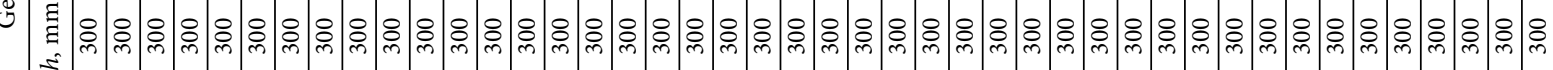

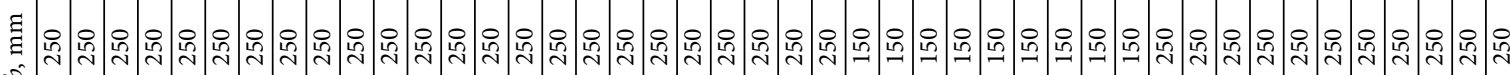

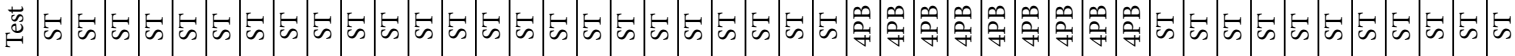
:

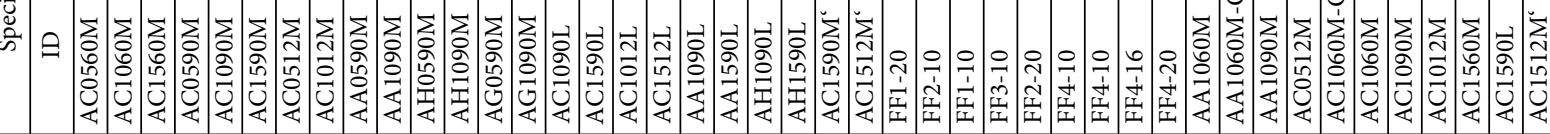

\begin{tabular}{|c|c|c|c|}
\hline ¿ & 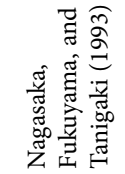 & 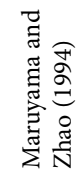 & 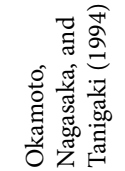 \\
\hline
\end{tabular}




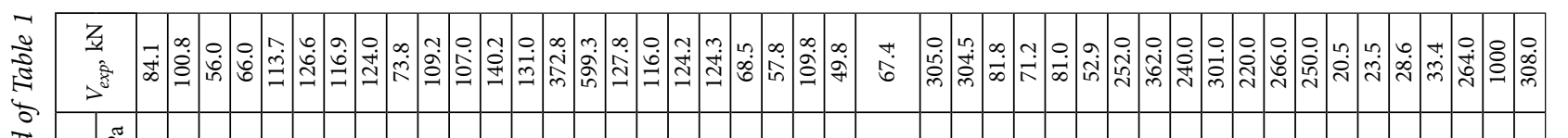
这

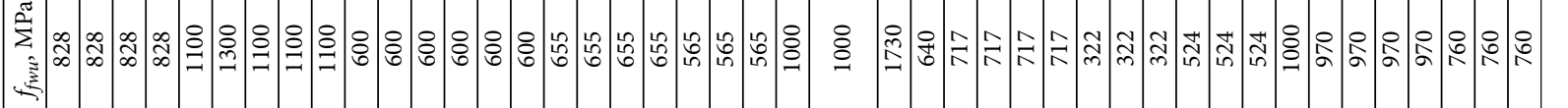

ชึ.

莀

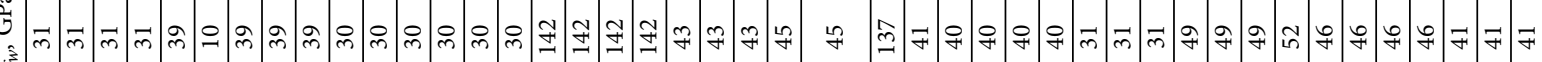

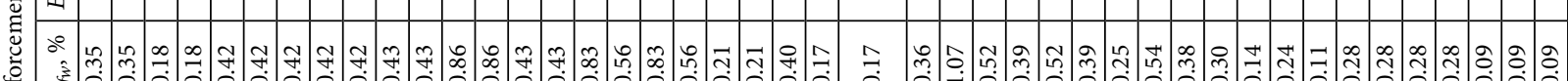

总

莺

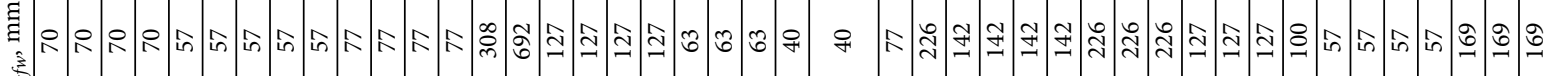
से

4 0 0 0 0 0 0 0 0 0 0 0 0 0 0 0 0 0 0 0 0 0 0 0 0 0 0 0 0 0 0 0 0 0 0 0 0 0 0 0 0 0 0 0 0 0 0 0

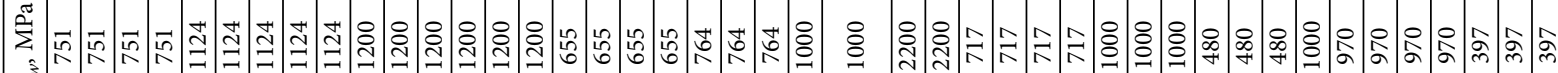

䓂

ป็

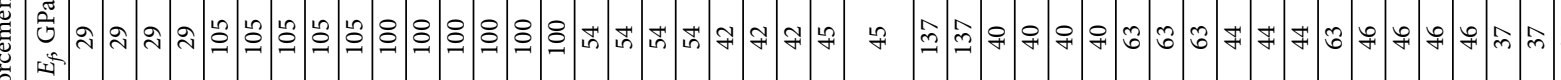

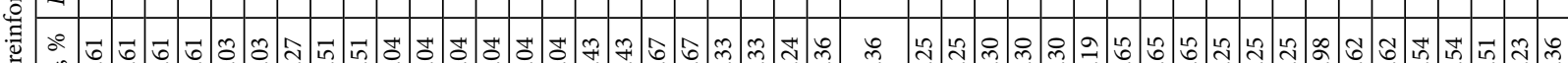

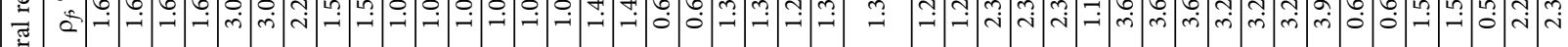

高

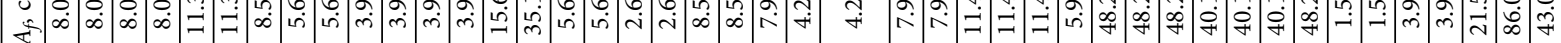

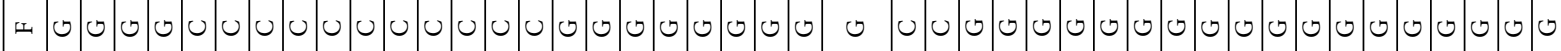

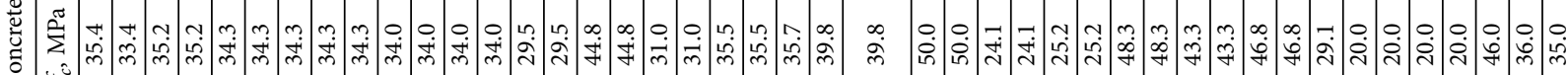

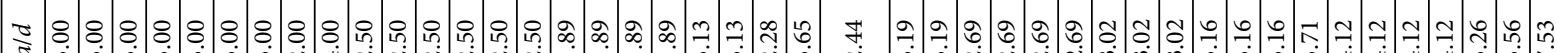

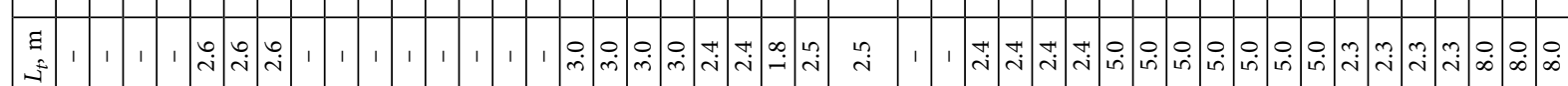

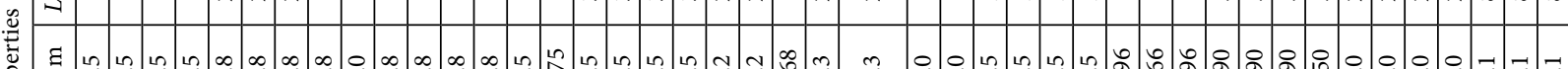

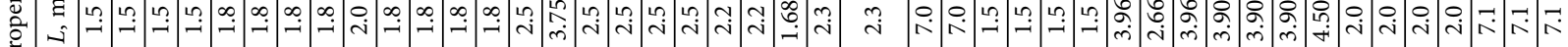

先

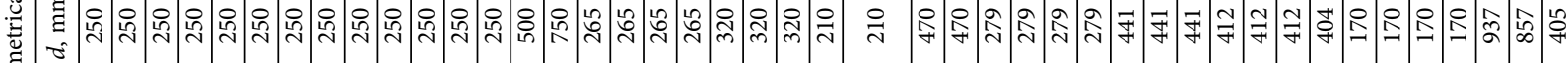

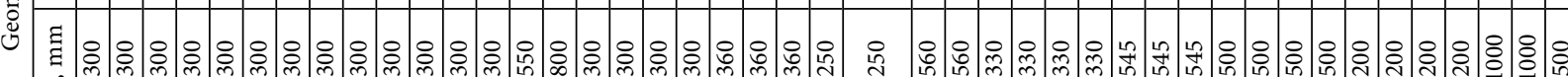

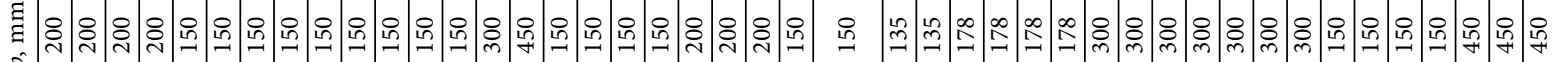

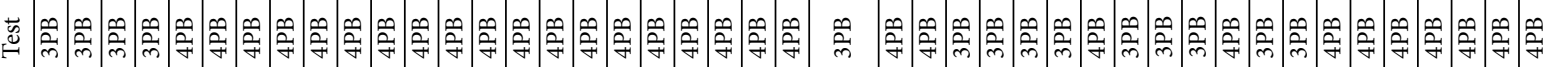
$\stackrel{\mathscr{Z}}{\stackrel{\Xi}{*}}$

竎



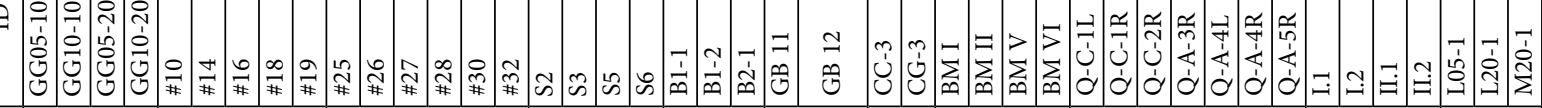
至 定 ह

\begin{tabular}{|c|c|c|c|c|c|c|c|c|c|c|c|}
\hline ᄒ & 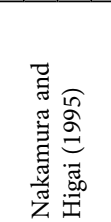 & 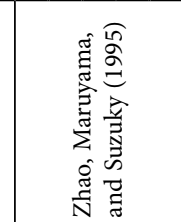 & 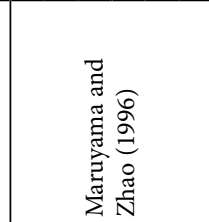 & 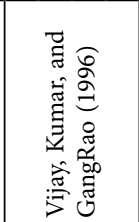 & 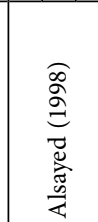 & 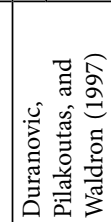 & 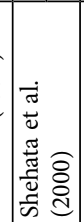 & 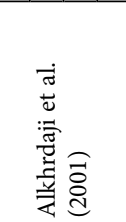 &  & 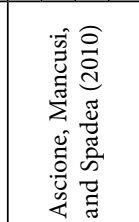 & 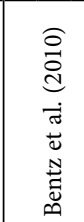 \\
\hline
\end{tabular}




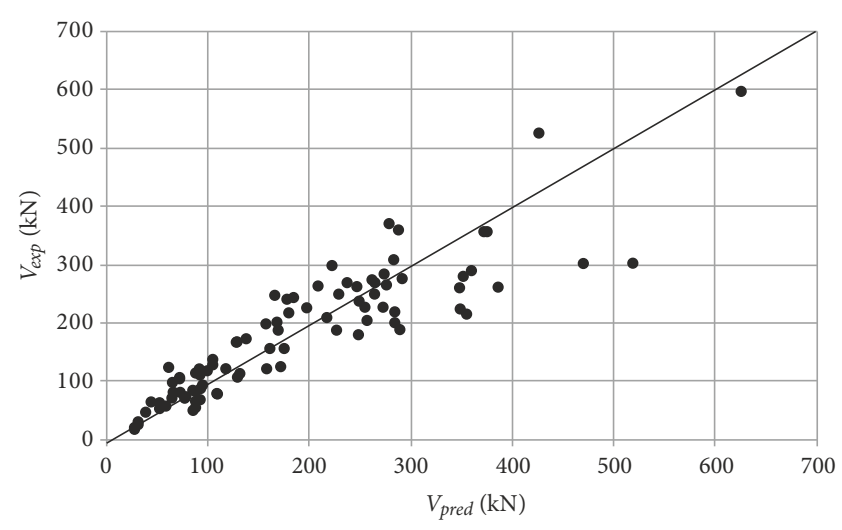

Figure 4. Experimental $V_{\text {exp }}$ versus predicted $V_{\text {pred }}$ shear strength by the CSA S806-12 shear design model

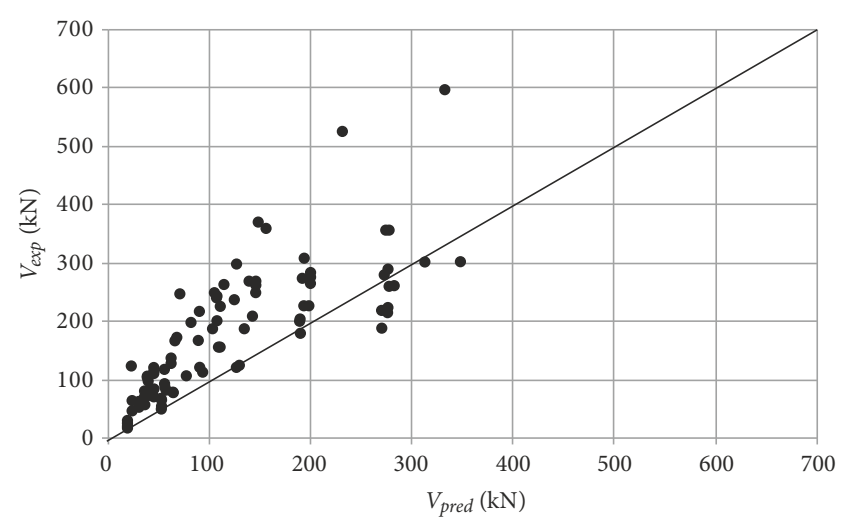

Figure 5. Experimental $V_{\text {exp }}$ versus predicted $V_{\text {pred }}$ shear strength by the CSA S6-14 shear design model

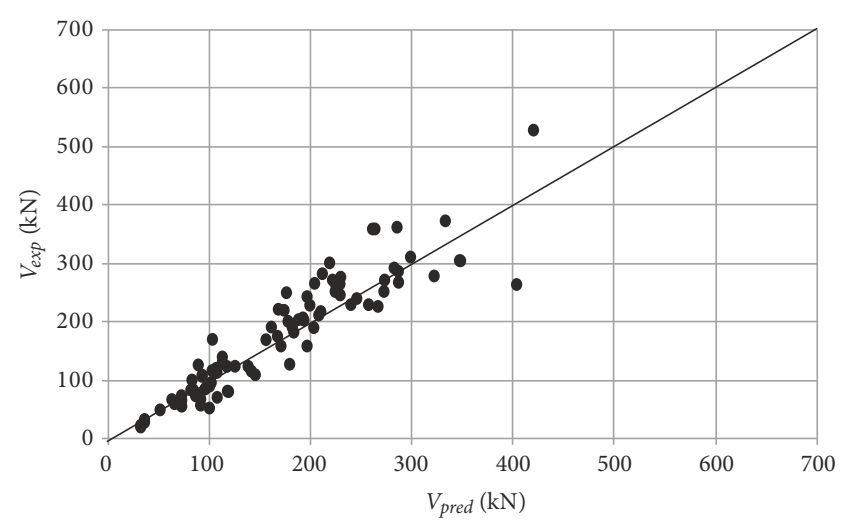

Figure 6. Experimental $V_{\text {exp }}$ versus predicted $V_{\text {pred }}$ shear strength by the Hegger et al. (2009) shear design model

Additional analysis of shear design models of Valivonis et al. (2015), CSA S806-12 and Hegger et al. (2009) was performed, because it was determined that these models are the most accurate. Correlation between ratio of experimental shear strength $V_{\text {exp }}$ and predicted shear strength $V_{\text {pred }}$ and different FRP reinforced concrete beam parameters was considered during this analysis. Compressive strength of concrete $f_{c}$ and transverse reinforcement ratio by its modulus of elasticity $E_{f w} \cdot \rho_{f w}$ was chosen as parameters for this analysis.

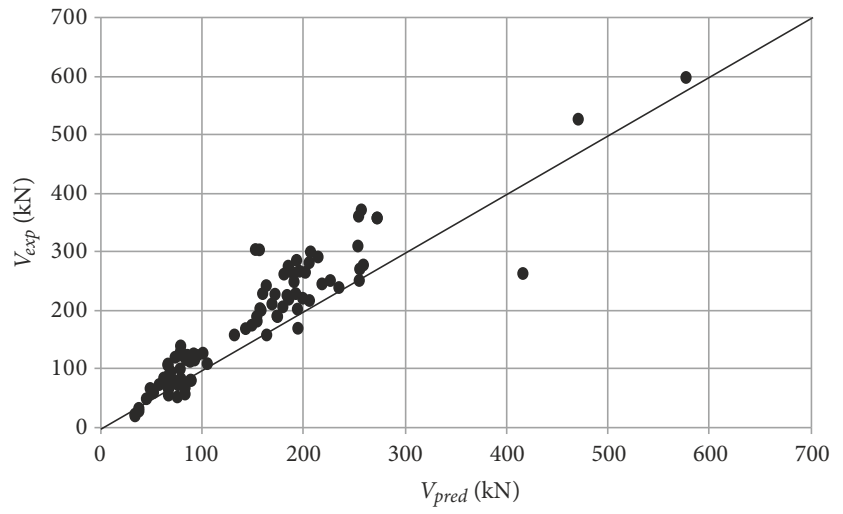

Figure 7. Experimental $V_{\text {exp }}$ versus predicted $V_{\text {pred }}$ shear strength by the Nehdi et al. (2007) shear design model



Figure 8. Experimental $V_{\text {exp }}$ versus predicted $V_{\text {pred }}$ shear strength by the Oller et al. (2015) shear design model

Table 2. The comparison of experimental and predicted shear strength for beams reinforced with FRP reinforcement

\begin{tabular}{|l|c|c|c|}
\hline \multicolumn{1}{|c|}{ Design model } & \multicolumn{3}{|c|}{$V_{\text {exp }} / V_{\text {pred }}$} \\
\hline Proposed model & 0.98 & $\begin{array}{c}\text { Standard } \\
\text { deviation }\end{array}$ & $\begin{array}{c}\text { Coefficient of } \\
\text { variation (\%) }\end{array}$ \\
\hline ACI 440.1R-06 & 1.24 & 0.53 & 26.0 \\
\hline CNR-DT 203/2006 & 0.64 & 0.16 & 42.3 \\
\hline CSA S806-12 & 1.05 & 0.27 & 25.3 \\
\hline CSA S6-14 & 1.79 & 0.75 & 41.8 \\
\hline Hegger et al. (2009) & 1.03 & 0.21 & 20.6 \\
\hline Nehdi et al. (2007) & 1.23 & 0.27 & 22.1 \\
\hline Oller et al. (2015) & 1.36 & 0.30 & 21.7 \\
\hline
\end{tabular}

Figures 9-11 shows the ratio $V_{\text {exp }} / V_{\text {pred }}$ in relation to the compressive concrete strength $f_{c}$ and to the transverse reinforcement ratio by its modulus of elasticity $E_{f w} \cdot \rho_{f w}$. For all three design models, the dispersion of $V_{\text {exp }} / V_{\text {pred }}$ values is smaller for lower values (between 20 and $25 \mathrm{MPa}$ ) of concrete compressive strength $f_{c}$. In addition, all three examined models perform in a similar manner in terms of correlation between $V_{\text {exp }} / V_{\text {pred }}$ and $f_{c}$.

Figures 10-11 presents the correlation between $V_{\text {exp }} /$ $V_{\text {pred }}$ and $E_{f w} \cdot \rho_{f w}$ for CSA S806-12 and Hegger et al. 
(2009) shear design models. It can be seen that the dispersion of $V_{\text {exp }} / V_{\text {pred }}$ values decreases with increasing values of $E_{f w} \cdot \rho_{f w}$. However for the proposed design model by Valivonis et al. (2015), it can be seen that dispersion not only does not decrease, but also slightly increases with increasing values of $E_{f w} \cdot \rho_{f w}$ (see Figure 9).

\section{Conclusions}

This paper presents an assessment of shear design models for FRP reinforced concrete beams available in literature. New shear design model is presented and included

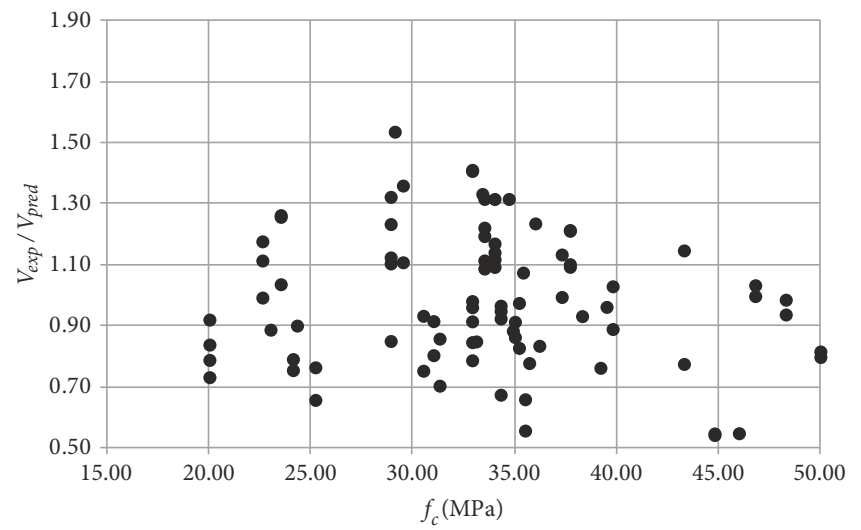

in comparative analysis. The following conclusions can be drawn from the present study:

1) the analysis of available shear design models showed that most of the models are based on a theory that shear capacity of FRP reinforced concrete beam consists of concrete shear resistance $V_{c}$ and FRP transverse reinforcement shear resistance $V_{f}$. Statistical analysis of predicted shear strength and experimental results show that this theory may be appropriate for shear design models of FRP reinforced concrete beams;

2) shear design model by Valivonis et al. (2015) was suggested for calculating shear capacity of FRP reinforced

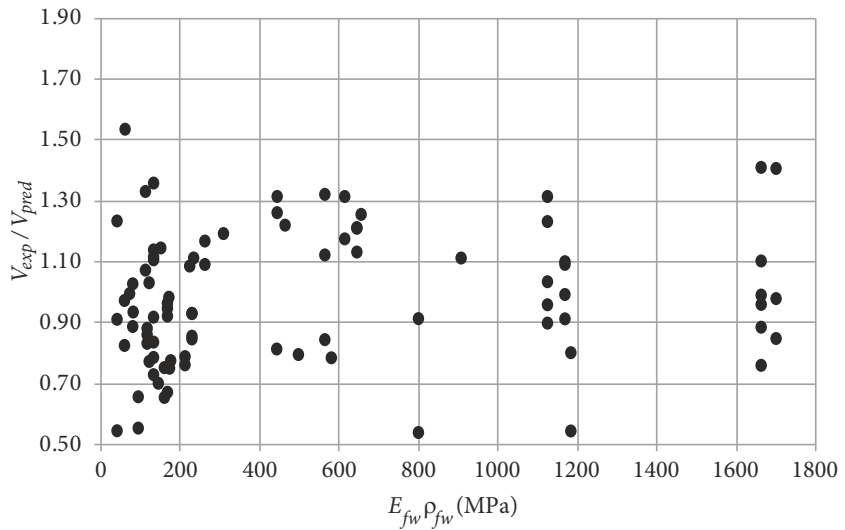

Figure 9. Correlation between $V_{\exp } / V_{p r e d}$ and $f_{c}$ and $E_{f w} \cdot \rho_{f w}$ according to proposed design model
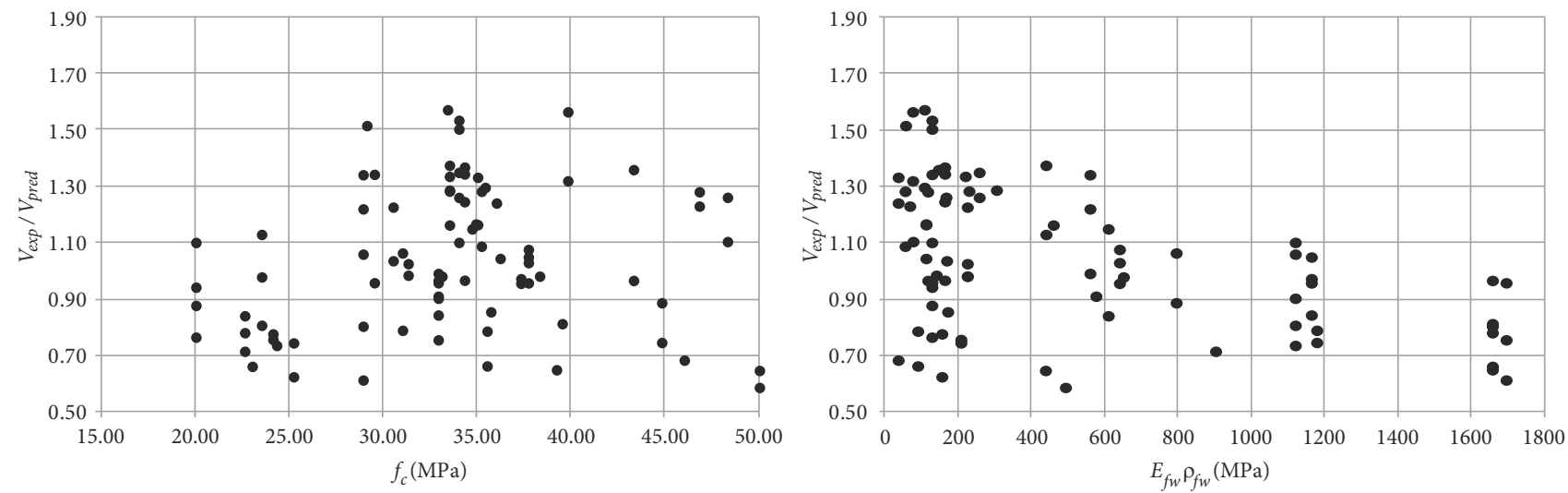

Figure 10. Correlation between $V_{\text {exp }} / V_{\text {pred }}$ and $f_{c}$ and $E_{f w} \cdot \rho_{f w}$ according to CSA S806-12 design model


Figure 11. Correlation between $V_{e x p} / V_{\text {pred }}$ and $f_{c}$ and $E_{f w} \cdot \rho_{f w}$ according to Hegger et al. (2009) design model 
concrete beams with FRP stirrups. Different mechanical properties of different types of FRP reinforcement are taken into account in this shear design model;

3) proposed shear design model by Valivonis et al. (2015) have been applied to predict the shear capacity of 88 specimens reinforced with FRP reinforcement. The results obtained by the proposed method are very good (mean value of $V_{\text {exp }} / V_{\text {pred }}$ is 0.98 , standard deviation is 0.26 , coefficient of variation is $26.0 \%$ )

4) correlation analysis of three most accurate design models was performed. It was observed that for all three design models, the dispersion of $V_{\text {exp }} / V_{\text {pred }}$ values is smaller for lower values of compressive strength of concrete $f_{c}$. But for the Valivonis et al. (2015) design model, the dispersion of $V_{\text {exp }} / V_{\text {pred }}$ values increases with increasing values of $E_{f w} \cdot \rho_{f w}$.

\section{Notation}

$a$ - shear span, mm;

$a_{0}$ - critical projection of shear cracking zone, $\mathrm{mm}$;

$A_{f}$ - area of FRP longitudinal reinforcement, $\mathrm{mm}^{2}$;

$A_{f w}$ - area of FRP shear reinforcement, $\mathrm{mm}^{2}$;

$b_{w}$ - beam width, mm;

$c$ - depth of compression zone at cracked transformed section, $\mathrm{mm}$;

$d$ - effective depth, $\mathrm{mm}$;

$d_{b}$ - diameter of the FRP bar in bent portion, $\mathrm{mm}$;

$d_{\text {max }}-$ maximum aggregate size, $\mathrm{mm}$;

$E_{c}$ - modulus of elasticity of concrete, GPa;

$E_{f}$ - modulus of elasticity of longitudinal FRP reinforcement, GPa;

$E_{f w}$ - modulus of elasticity of FRP shear reinforcement, $\mathrm{GPa}$;

$E_{s}$ - modulus of elasticity of steel reinforcement, GPa;

$f_{c}$ - compressive strength of concrete, MPa;

$f_{c r}$ - cracking strength of concrete, $\mathrm{MPa}$;

$f_{c t}$ - tensile strength of concrete, $\mathrm{MPa}$;

$f_{f b}$ - tensile strength of FRP bent bar, MPa;

$f_{f r}$ - reduced tensile strength of the FRP reinforcement, $\mathrm{MPa}$;

$f_{f w}$ - stress level in the FRP shear reinforcement at ultimate state, MPa;

$f_{f w u}$ - tensile strength of FRP shear reinforcement, MPa;

$G_{f}$ - fracture energy of concrete;

$h$ - beam height, mm;

$k$ - coefficient, which accounts the decreasing depth of neutral axis;

$L$ - span length, mm;

$L_{t}$ - overall length of the member, $\mathrm{mm}$;

$M$ - bending moment, $\mathrm{kNm}$;

$n_{f}$ - modular ratio of modulus of elasticity of FRP rein-

forcement and concrete; $r_{b}$ - bending radius of FRP bar, mm;

$s$ - spacing of shear reinforcement, $\mathrm{mm}$;

$s_{z e}$ - effective crack spacing for members without stirrups, $\mathrm{mm}$;

$V$ - shear load, kN;

$V_{c}$ - concrete contribution to shear capacity, $\mathrm{kN}$;

$V_{c c}$ - shear resisted by the un-cracked concrete zone, $\mathrm{kN}$;

$v_{c c}$ - dimensionless form of shear resisted by the uncracked concrete zone;

$V_{\text {exp }}$ - experimental shear strength, $\mathrm{kN}$;

$V_{f}$ - FRP transverse reinforcement contribution to shear capacity, $\mathrm{kN}$;

$v_{f w}$ - shear strength caused by web reinforcement in the structural member's linear meter, $\mathrm{N} / \mathrm{mm}$;

$V_{\text {pred }}$ - predicted shear strength, $\mathrm{kN}$;

$V_{t}$ - shear resisted by transverse reinforcement crossing the diagonal critical shear crack, $\mathrm{kN}$;

$v_{t}$ - dimensionless form of shear resisted by transverse reinforcement crossing the diagonal critical shear crack;

$V_{u}$ - shear capacity of FRP reinforced concrete beam, $\mathrm{kN}$;

$V_{u, \max }$ - concrete contribution corresponding to shear failure due to crashing of the web, $\mathrm{kN}$;

$V_{w}$ - shear resisted by tensile stresses transferred along the crack, $\mathrm{kN}$;

$v_{w}$ - dimensionless form of shear resisted by tensile stresses transferred along the crack;

$z$ - lever arm of internal forces, $\mathrm{mm}$;

$\alpha_{c w}$ - coefficient taking into account the state of the stress in the compression chord;

$\gamma_{f, \Phi}-$ partial factor to account for the bending effect;

$\varepsilon_{f w u}$ - ultimate strain of the transverse FRP stirrups;

$\varepsilon_{f w, m}$ - mean strain at the stirrups crossing the crack;

$\varepsilon_{x}$ - longitudinal strain at midheight of the cross section;

$\zeta$ - coefficient which accounts the size effect on the shear failure;

$\theta$ - angle between the concrete compression strut and the beam axis perpendicular to the shear force, ${ }^{\circ}$;

$\lambda$ - factor accounting for concrete density;

$v_{1}$ - strength reduction factor for concrete cracked in shear;

$\xi$ - relative neutral axis depth;

$\rho_{f}$ - longitudinal FRP reinforcement ratio;

$\rho_{f w}$ - FRP shear reinforcement ratio;

$\tau$ - shear stress, MPa;

$\varphi_{c 2}, \varphi_{c 3}, \varphi_{c 4}$ - coefficients which estimate concrete's properties;

$\varphi_{f}$ - coefficient which estimate the influence of FRP flexural reinforcement for the concrete shear resistance;

$\phi_{c}$ - resistance factor for concrete;

$\phi_{f}$ - resistance factor for FRP reinforcement. 


\section{References}

Ahmed, E. A., El-Salakawy, E. F., \& Benmokrane, B. (2010). Performance evaluation of glass fiber-reinforced polymer shear reinforcement for concrete beams. ACI Structural Journal, 107(1), 53-62.

Alam, M., \& Hussein, A. (2012). Effect of member depth on shear strength of high-strength fiber-reinforced polymer-reinforced concrete beams. Journal of Composites for Construction, 16(2), 119-126.

https://doi.org/10.1061/(ASCE)CC.1943-5614.0000248

Alkhrdaji, T., Wideman, M., Belarbi, A., \& Nanni, A. (2001, October 10-12). Shear strength of GFRP RC beams and slabs. In Proceedings of the International Conference, Composites in Construction-CCC (pp. 409-414). Porto, Portugal: A. A. Balkema.

Alsayed, S. H. (1998). Flexural behaviour of concrete beams reinforced with GFRP bars. Cement and Concrete Composites, 20(1), 1-11. https://doi.org/10.1016/S0958-9465(97)00061-9

American Concrete Institute (ACI). (2006). Guide for the design and construction of concrete reinforced with FRP bars (ACI 440.1R-06). Farmington Hills, MI: Author.

Ascione, L., Mancusi, G., \& Spadea, S. (2010). Flexural behaviour of concrete beams reinforced with GFRP bars. Strain, 46(5), 460-469. https://doi.org/10.1111/j.1475-1305.2009.00662.x

Benmokrane, B., Ali, A. H., Mohamed, H. M., Robert, M., \& ElSafty, A. (2016). Durability performance and service life of CFCC tendons exposed to elevated temperature and alkaline environments. Journal of Composites for Construction, 20(1), 1-13. https://doi.org/10.1061/(ASCE)CC.1943-5614.0000606

Bentz, E. C., Massam, L., \& Collins, M. P. (2010). Shear strength of large concrete members with FRP reinforcement. Journal of Composites for Construction, 14(6), 637-646.

https://doi.org/10.1061/(ASCE)CC.1943-5614.0000108

Canadian Standards Association (CSA). (2012). Design and construction of buildings components with fiber-reinforced polymers (CSA S806-12). Toronto, Canada: Author.

Canadian Standards Association (CSA). (2014). Canadian highway bridge design code (CSA S6-14). Rexdale, ON: Author.

Duranovic, N., Pilakoutas, K., \& Waldron, P. (1997, October 14-16). Tests on concrete beams reinforced with glass fiber reinforced plastic bars. In Proceedings of the $3^{\text {rd }}$ International Symposium on Non-metallic (FRP) Reinforcement for Concrete Structure (FRPRCS-3) (pp. 479-486). Japan Concrete Institute, Sapporo, Japan.

El-Sayed, A. K., \& Benmokrane, B. (2008). Evaluation of the new Canadian highway bridge design code shear provisions for concrete beams with fiber-reinforced polymer reinforcement. Canadian Journal of Civil Engineering, 35(6), 609-623. https://doi.org/10.1139/L08-009

El-Sayed, A. K., El-Salakawy, E. F., \& Benmokrane, B. (2006). Shear strength of FRP-reinforced concrete beams without transverse reinforcement. ACI Structural Journal, 103(2), 235-243.

El-Sayed, A. K., El-Salakawy, E., \& Benmokrane, B. (2007). Mechanical and structural characterization of new carbon FRP stirrups for concrete members. Journal of Composites for Construction, 11(4), 352-362. https://doi.org/10.1061/(ASCE)1090-0268(2007)11:4(352)

Fico, R., Prota, A., \& Manfredi, G. (2008). Assessment of Eurocode-like design equations for the shear capacity of FRP RC members. Composites Part B: Engineering, 39(5), 792-806. https://doi.org/10.1016/j.compositesb.2007.10.007
Guadagnini, M., Pilakoutas, K., \& Waldron, P. (2006). Shear resistance of FRP RC beams: Experimental study. Journal of Composites for Construction, 10(6), 464-473.

https://doi.org/10.1061/(ASCE)1090-0268(2006)10:6(464)

Hegger, J., Niewels, J., \& Kurth, M. (2009). Shear analysis of concrete members with fiber-reinforced polymers (FRP) as internal reinforcement. In $9^{\text {th }}$ International Symposium on Fibre-Reinforced Polymer Reinforcement for Conrete Structures, FRPRCS-9 (pp. 1-8). University of Adelaide, Sydney, Australia.

Hoult, N. A., Sherwood, E. G., Bentz, E. C., \& Collins, M. P. (2008). Does the use of FRP reinforcement change the oneway shear behavior of reinforced concrete slabs?, Journal of Composites for Construction, 12(2), 125-133. https://doi.org/10.1061/(ASCE)1090-0268(2008)12:2(125)

Italian Research Council. (2007). Guide for the design and construction of concrete structures reinforced with fiber-reinforced polymer bars (CNR-DT 203/2006). Rome, Italy: Author.

Japan Society of Civil Engineering (JSCE). (1997). Recommendation for design and construction of concrete structures using continuous fiber reinforcing materials. Tokyo, Japan: Author.

Maruyama, K., \& Zhao, W. J. (1994, July 24-28). Flexural and shear behaviour of concrete beams reinforced with FRP rods. In Proceedings of the International Conference on Corrosion and Corrosion Protection of Steel in Concrete, (pp. 1330-1339). University of Sheffield, Sheffield, England.

Maruyama, K., \& Zhao, W. J. (1996). Size effect in shear behavior of FRP reinforced concrete beams. In $2^{\text {nd }}$ International Conference on Advanced Composite Materials in Bridges and Structures (pp. 227-234). Canadian Society for Civil Engineering, Montreal, Canada.

Mohamed, H. M., Afifi, M. Z., \& Benmokrane, B. (2014). Performance evaluation of concrete columns reinforced longitudinally with FRP bars and confined with FRP hoops and spirals under axial load. Journal of Bridge Engineering, 19(7), 1-12. https://doi.org/10.1061/(ASCE)BE.1943-5592.0000590

Mohamed, H. M., \& Benmokrane, B. (2013). Design and performance of reinforced concrete water chlorination tank totally reinforced with GFRP bars: case study. Journal of Composites for Construction, 18(1), 1-11.

Nagasaka, T., Fukuyama, H., \& Tanigaki, M. (1993). Shear performance of concrete beams reinforced with FRP stirrups. Special Publication, FRPRCS-1, 138, 789-812.

Nakamura, H., \& Higai, T. (1995). Evaluation of shear strength of concrete beams reinforced with FRP. Doboku Gakkai Ronbunshu, 1995(508), 89-100.

https://doi.org/10.2208/jscej.1995.508_89

Nanni, A., \& Faza, S. (2002). Designing and constructing with FRP bars: An emerging technology. ACI Concrete International, 24(11), 53-58.

Natural Sciences and Engineering Research Council of Canada. (2010). Bridging the gap: Composites extend infrastructure life. Retrieved from http://www.nserc-crsng.gc.ca/Media-Media/ ImpactStory-ArticlesPercutant_eng.asp?ID=1047

Nehdi, M., El Chabib, H., \& Aly Said, A. (2007). Proposed shear design equations for FRP-reinforced concrete beams based on genetic algorithms approach. Journal of Materials in Civil Engineering, 19(12), 1033-1042. https://doi.org/10.1061/(ASCE)0899-1561(2007)19:12(1033)

Niewels, J. (2008). Zum tragverhalten von botonbauteilen mit faserverbundkunststoff-bewerhung (PhD Thesis). Aachen University, Germany. 
Okamoto, T., Nagasaka, T., \& Tanigaki, M. (1994). Shear capacity of concrete beams using FRP reinforcement. Journal of Structural and Construction Engineering, 455(59), 127-136.

https://doi.org/10.3130/aijs.59.127_1

Oller, E., Mari, A., Bairan, J. M., \& Cladera, A. (2015). Shear design of reinforced concrete beams with FRP longitudinal and transverse reinforcement. Composites Part B: Engineering, 74, 104-122. https://doi.org/10.1016/j.compositesb.2014.12.031

Perera, R., Arteaga, A., \& Diego, A. D. (2010). Artificial intelligence techniques for prediction of the capacity of RC beams strengthened in shear with external FRP reinforcement. Composite Structures, 92(5), 1169-1175.

https://doi.org/10.1016/j.compstruct.2009.10.027

Razaqpur, A., \& Spadea, S. (2014). Shear strength of FRP reinforced concrete members with stirrups. Journal of Composites for Construction, 19(1), 1-15.

Shehata, E., Morphy, R., \& Rizkalla, S. (2000). Fibre reinforced polymer shear reinforcement for concrete members: behaviour and design guidelines. Canadian Journal of Civil Engineering, 27(5), 859-872. https://doi.org/10.1139/100-004

Tottori, S., \& Wakui, H. (1993). Shear capacity of RC and PC beams using FRP reinforcement. ACI Structural Journal, 138, 615-632.

Tureyen, A. K., \& Frosch, R. J. (2002). Shear tests of FRP-reinforced concrete beams without stirrups. ACI Structural Journal, 99(4), 427-434.

Valivonis, J., Budvytis, M., Atutis, M., Atutis, E., \& Juknevičius, L. (2015). Study on shear resistance of fiber-reinforced polymerreinforced concrete beams. Advances in Mechanical Engineering, 7(7), 1-17. https://doi.org/10.1177/1687814015593873

Vijay, P. V., Kumar, S. V., \& GangRao, H. V. S. (1996). Shear and ductility behavior of concrete beams reinforced with GFRP rebars. In $2^{\text {nd }}$ International Conference on Advanced Composite Materials in Bridges and Structures, ACMBS (pp. 217-226). Canadian Society for Civil Engineering, Montreal, Canada.

Zhao, W. J., Maruyama, K., \& Suzuky, H. (1995). Shear behavior of concrete beams reinforced by FRP rods as longitudinal and shear reinforcement. In RILEM Proceedings, FRPRCS-2 (pp. 352-359). Ghent, Belgium: E. \& F. N. Spon. 